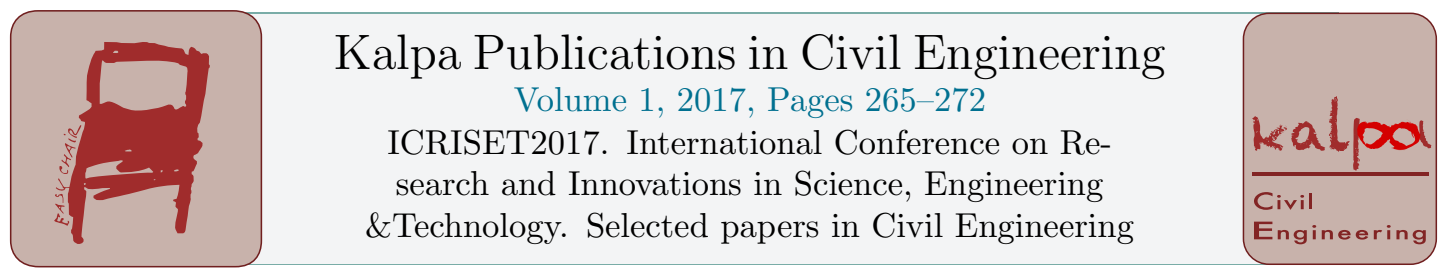

\title{
Estimation of Net Irrigation Requirements of Crops in the Deterministic and Stochastic Regimes for Limbasi Canal Command Area
}

\author{
S. S. Khandelwal ${ }^{1, *}$ and Dr. S. D. Dhiman ${ }^{2}$ \\ ${ }^{1}$ Faculty of Technology, Dharmsinh Desai University, Nadiad, India \\ ${ }^{2}$ Birla Vishvakarma Mahavidyalaya, Vallabh Vidyanagar, India. \\ sskddu@gmail.com, sddhiman@bvmengineering.ac.in
}

\begin{abstract}
Estimation of Net Irrigation Requirement (NIR) of crops is essential for agricultural planning, irrigation scheduling, regional water balance studies and optimal allocation of land and water resources in a canal command area. In the present study, NIR estimation of different crops of Limbasi Canal command area, Gujarat, India is carried out in the deterministic and stochastic regimes for nineteen years of available data. In the deterministic regime, the estimated average NIR of 19 years for kharif crops paddy \& vegetables was $229.8 \& 92.9 \mathrm{~mm}$; rabi crops sorghum, tobacco, wheat \& vegetables was 355.5, 391, 427.2 \& 407.1mm and hot weather crops paddy, pearl millet \& vegetables was $863.9,600.6 \& 754.7 \mathrm{~mm}$ respectively. In the stochastic regime, NIR of different crops was predicted at Probability of Exceedance (PE) levels of 0.02, 0.05, $0.08,0.10,0.15,0.20,0.25,0.35$ and 0.40 using 19 years of NIR. MATLAB was used for prediction of NIR. The goodness of fit was tested by Kolmogorov - Smirnov test and normal distribution was found as the best fit.
\end{abstract}

\section{Introduction}

Net Irrigation Requirement (NIR) of crops mainly depends on reference crop evapotranspiration $\left(\mathrm{ET}_{\mathrm{o}}\right)$ and hence, accurate estimate of $\mathrm{ET}_{\mathrm{o}}$ is a key component in hydrological studies. $\mathrm{ET}_{\mathrm{o}}$ depends on several climatological factors, such as temperature, humidity, wind speed, radiation, type and stage of growth of the crop and so on.

$\mathrm{ET}_{\mathrm{o}}$ can be measured directly using lysimeter or water balance approaches. However, measurement of $\mathrm{ET}_{\mathrm{o}}$ using lysimeter is a time-consuming method. It also needs precise and carefully planned experiments. Hence, it is not always possible to measure $\mathrm{ET}_{\mathrm{o}}$ by using lysimeter. Under such

\footnotetext{
${ }^{*}$ Corresponding author
} 
circumstances, $\mathrm{ET}_{\mathrm{o}}$ is estimated indirectly using climatological data. The indirect methods of $\mathrm{ET}_{\mathrm{o}}$ estimation using climatological data vary from empirical relationships to complex methods such as the Penman Monteith method based on physical processes. The different methods of $\mathrm{ET}_{\mathrm{o}}$ estimation can be grouped into temperature methods, radiation methods, combination theory types and pan evaporation methods.

FAO-56 Penman-Monteith method was used by [1] for estimation of $\mathrm{ET}_{0}$ for different irrigation project sites in Andhra Pradesh, India. Estimation of $\mathrm{ET}_{\mathrm{o}}$ for eight irrigation project sites located in Andhra Pradesh, India was carried out by [2]. $\mathrm{ET}_{\mathrm{o}}$ estimation for the humid areas of Agartala (Tripura) and Umiam (Meghalaya), India using revised Blaney Criddle, Christiansen and Thornthwaite methods was carried out by [3]. Hargreaves - Samani method for ET $_{0}$ estimation was used by [4], [5] and [6] for different locations. A comparative study of $\mathrm{ET}_{\mathrm{o}}$ estimation in the Limbasi canal command area using Hargreaves - Samani method and Modified Penman's method was carried out by [7]. The FAO-56 Penman-Monteith and two Valiantzas equations' accuracy were evaluated by [8] for daily $\mathrm{ET}_{\mathrm{o}}$ estimation under limited climatic data and four other radiation based $\mathrm{ET}_{\mathrm{o}}$ equations across Tanzania and swestern Kenya.

Crop water requirement is estimated using $\mathrm{ET}_{\mathrm{o}}$ values. Water requirement of crops under the command area of Singnapur and Lohagaon minors Jayakwadi project, India, was estimated by [9] using CRIWAR software. Water requirement of crops of the Anantapur district, Andhra Pradesh, India was estimated by [10] using CROPWAT model. Irrigation water requirement of different crops of Limbasi canal command area, Gujarat, India was estimated by [11]. Water requirement of different crops of middle Gujarat, India was estimated by [12] using FAO Penman- Monteith method.

In all the above studies, estimation of NIR was carried out in the deterministic regime. However, dependence of NIR on precipitation, evapotranspiration and other climatic factors makes it stochastic in nature. The chance aspect of NIR is due to randomness in precipitation, evapotranspiration and other similar climatic conditions of irrigated area [13]. Hence, estimation of NIR in the stochastic regime is necessary for real field situations. Forecasting of irrigation water requirement of paddy field area using the fuzzy theory was carried out by [14]. NIR of crops of at various Probability of Exceedance (PE) levels was estimated by [6], [13] and [15]. Uncertainties in the estimation of NIR using fuzzy logic approach were quantified by [16]. Usefulness of multi-model ensemble predictions and sophisticated model averaging techniques in predicting irrigation demand was investigated by [17], in which, irrigation water requirement for wheat in the Murray-Darling Basin, Australia was estimated and the importance of the model structural versus model parametric uncertainty for irrigation simulations was investigated. The model structural uncertainty among reference ET was found more important than model parametric uncertainty introduced by crop coefficients.

\section{Materials and Methods}

\subsection{Study Area}

The study area is a Limbasi canal command area situated between latitudes of $22^{\circ} 31^{\prime} 33.2^{\prime \prime}$ to $22^{\circ}$ $36^{\prime} 11.8^{\prime \prime} \mathrm{N}$ and longitudes of $72^{\circ} 32^{\prime}{ }^{\prime} 8.6^{\prime}$ ' to $72^{\circ} 48^{\prime} 18.7^{\prime}$ 'E. Fig.1 shows the index plan of Limbasi canal [18]. It has a Gross Command Area (GCA) of 23405 ha and Culturable Command Area (CCA) of 15764 ha. The study area is situated at an elevation from 35 to $90 \mathrm{~m}$ above MSL having flat topography towards the Gulf of Cambay with an average slope gradient less than $1 \%$ in the length of $58 \mathrm{~km}$. There are no well defined natural existing drains in the command area. 


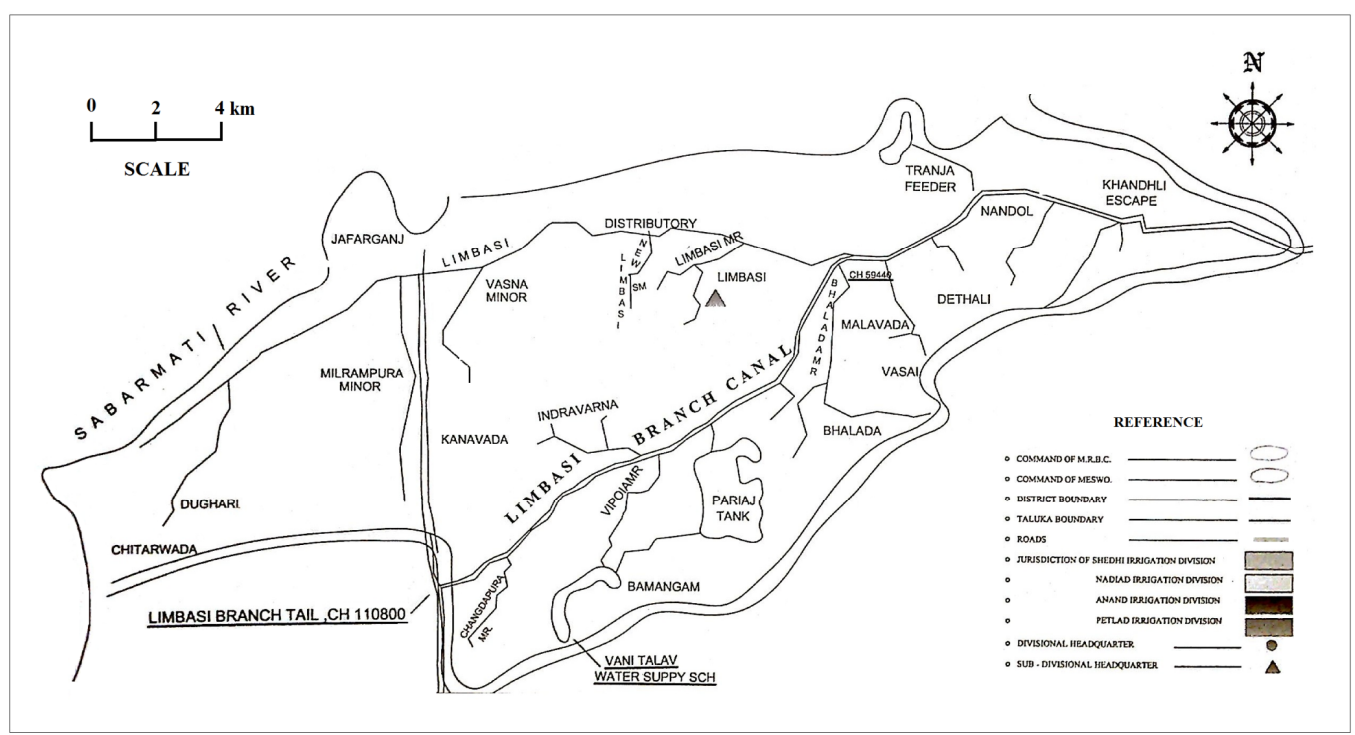

Figure 1: Index map of Limbasi canal (Source - Mahi Irrigation Circle, Nadiad)

Paddy is the major crop in kharif season and covers about $97 \%$ of the area in the kharif season. Wheat is the major crop in rabi season and covers about $93 \%$ of the area in the rabi season. Pearl millet sorghum, tobacco, and vegetables are also cultivated in the command area.

The study area is located in the agro-climatic zone GJ-3 (middle Gujarat zone) with semi - arid climate. The maximum recorded temperature in the study area was $46.7^{\circ} \mathrm{C}$ in June, 2010 while minimum temperature was $4.2^{\circ} \mathrm{C}$ in the February, 2005. The average annual rainfall is $786 \mathrm{~mm}$ with most of the rainfall restricted to monsoon months of June to September. The maximum value of relative humidity was $100.0 \%$ in July (and August) 2008 while the minimum relative humidity was $3.6 \%$ in December 2011 [19]. The mean annual soil temperature is more than $22^{\circ} \mathrm{C}$ and the difference between mean summer and mean winter soil temperature is more than $5^{\circ} \mathrm{C}[20]$.

The study area is bounded on north by river Watrak, on the south by Gulf of Cambay, on east by river Shedhi and on west by the river Sabarmati. The soil of north-east part of the study area is influenced by river Shedhi which forms the complex nature of parent material mainly like sandstone, schist and phylites. The soil of this area is light to medium texture with yellowish brown to dark brown in colour. The soil of the western part of the study area is influenced by the river Watrak and Sabarmati which forms the complex nature of parent material, mainly like basalt and granite. The soil of this area is medium to heavy in texture with dark brown to very dark grayish brown in colour.

In the surface soil (depth up to $30 \mathrm{~cm}$ below ground level) nearly $39.2 \%$ area exhibit coarse to medium texture while in the sub-surface soil (depth from 30 to $90 \mathrm{~cm}$ below ground level) nearly $31.9 \%$ area exhibits coarse to medium texture. Nearly $60.8 \%$ area in the surface soil and $68.1 \%$ area in sub-surface soil have moderately fine to fine texture. In the entire command of Limbasi branch canal, the depth of the soil is more than $90 \mathrm{~cm}$ i.e. very deep [20]. The infiltration rate vary from 0.14 to $1.38 \mathrm{~cm} / \mathrm{hr}$.

\subsection{Data Acquisition and Analysis}

Daily rainfall data of six rain gauge stations namely Matar, Limbasi, Petlad, Khambhat, Sojitra and Kanewal located in and around the study area were collected from [18]. The length of data collection was 23 years (1990 to 2012). 
Daily minimum and maximum temperature data of the Navagam weather station located nearby the Limbasi canal command area were collected from [19]. The length of data collection was 20 years (1993 to 2013 except the year 2001 for which data were not available).

\subsection{Reference Crop Evapotranspiration Estimation}

Reference crop evapotranspiration $\left(\mathrm{ET}_{\mathrm{o}}\right)$ is to be estimated first for the estimation of Net Irrigation Requirement (NIR) of crops. Several methods are available for estimation of $\mathrm{ET}_{\mathrm{o}}$. For the study area, daily $\mathrm{ET}_{\mathrm{o}}$ estimation using Hargreaves - Samani method was carried out by [7] and compared with daily $\mathrm{ET}_{\mathrm{o}}$ estimation using Modified Penman's method carried out by Water and Land Management Institute (WALMI), Anand, Gujarat. Several comparisons were obtained through the simple linear regression analysis technique and a set of statistical parameters.

It was found that there was a good agreement between $\mathrm{ET}_{\mathrm{o}}$ estimates by two methods. It was also found that Modified Penman method requires detailed climatological data (which are not often available with required degree of preciseness), while Hargreaves-Samani method uses limited data like air temperature and extraterrestrial solar radiation only to give reasonably good estimate of $\mathrm{ET}_{\mathrm{o}}$. Hence, in the present analysis, Hargreaves-Samani method [21] is adopted for ET ${ }_{0}$ estimation of the study area. This method computes daily mean $\mathrm{ET}_{\mathrm{o}}$ using (1).

$$
E T_{O}=0.0023 * R_{a} *\left(T_{\text {avg }}+17.8\right) * \sqrt{\left(T_{\max }-T_{\min }\right)}
$$

Where, $\mathrm{ET}_{\mathrm{o}}=$ reference crop evapotranspiration $(\mathrm{mm} /$ day $) ; \mathrm{R}_{\mathrm{a}}=$ extraterrestrial solar radiation $\left(\mathrm{mm} /\right.$ day); $\mathrm{T}_{\text {avg }}, \mathrm{T}_{\max }$ and $\mathrm{T}_{\min }$ are daily average, maximum and minimum air temperatures $\left({ }^{\circ} \mathrm{C}\right)$. The values of extraterrestrial solar radiation $\left(\mathrm{R}_{\mathrm{a}}\right)$ depend on month of the year and latitude of the place as given by [22]. Daily $\mathrm{ET}_{\mathrm{o}}$ values as estimated by (4) were multiplied by number of days in a given month to determine monthly $\mathrm{ET}_{\mathrm{o}}$ values.

\subsection{Potential Crop Evapotranspiration Estimation}

Potential crop evapotranspiration $\left(\mathrm{ET}_{\mathrm{c}}\right)$ of different crops of the study area were estimated from reference crop evapotranspiration $\left(\mathrm{ET}_{\mathrm{o}}\right)$ by using (2).

$E T_{c}=E T_{o} * K_{C}$

Where, $\mathrm{ET}_{\mathrm{c}}=$ potential crop evapotranspiration $(\mathrm{mm}) ; \mathrm{ET}_{\mathrm{o}}=$ reference crop evapotranspiration $(\mathrm{mm})$; $\mathrm{K}_{\mathrm{c}}=$ crop coefficient for a given crop.

Monthly $\mathrm{ET}_{\mathrm{c}}$ values of different crops of the study area were determined by multiplying monthly $\mathrm{ET}_{\mathrm{o}}$ values by suitable crop coefficient $\left(\mathrm{K}_{\mathrm{c}}\right)$. For $\mathrm{K}_{\mathrm{c}}$ values of different crops of the study area, reference was made to [23].

\subsection{Net Irrigation Requirement (NIR) Estimation}

NIR of different crops of the study area was estimated from potential crop evapotranspiration $\left(\mathrm{ET}_{\mathrm{c}}\right)$ by using (3).

$N I R=E T_{c}-R_{e f f}$

Where, NIR = net irrigation requirement $(\mathrm{mm}) ; \mathrm{ET}_{\mathrm{c}}=$ potential crop evapotranspiration $(\mathrm{mm}) ; \mathrm{R}_{\mathrm{eff}}=$ effective rainfall (mm).

Monthly NIR of different crops of the study area was estimated by $\mathrm{ET}_{\mathrm{c}}$ and $\mathrm{R}_{\text {eff }}$ values. Effective rainfall $\left(\mathrm{R}_{\text {eff }}\right)$ was determined by U.S. Department of Agriculture (USDA), Soil Conservation Service (SCS) method [24]. According to this method the effective rainfall $\left(R_{\text {eff }}\right)$ for paddy was estimated as $\mathrm{R}_{\text {eff }}(\mathrm{t})=0.8 * \mathrm{R}(\mathrm{t})$, while for non-paddy crops, it was estimated as $\mathrm{R}_{\text {eff }}(\mathrm{t})=0.7 * \mathrm{R}(\mathrm{t})$. Effective rainfall was considered for the monsoon months of June to September only, as in the remaining months, significant rainfall does not occur regularly in the command area and hence, effective rainfall is zero during this period. If the monthly NIR was negative (for $R_{\text {eff }}>E_{c}$ ), for a particular crop, then the 
NIR of that crop for that month was considered as zero. From monthly NIR, seasonal NIR of crops was computed by adding the monthly NIR of corresponding crops [13].

In the present analysis, NIR of different crops of the study area in the deterministic regime was estimated for 19 years (1993-1994 to 2012-2013). For prediction of NIR values in the stochastic regime at various Probability of Exceedance (PE) levels, NIR in the deterministic regime for 19 years was used as input in the MATLAB. Weibull's distribution was considered as reference. The goodness of fit was tested by Kolmogorov - Smirnov test and normal distribution was found as best fit. The expected NIR values at Probability of Exceedance (PE) levels of 0.02, 0.05, 0.08, 0.10, 0.15, 0.20, $0.25,0.35$ and 0.40 were obtained in the stochastic regime.

\section{Results and Discussions}

In the deterministic regime, NIR of different crops of the study area was estimated for 19 years (1993-1994 to 2012-2013). Details are given in Table-1. The estimated average NIR of 19 years for kharif crops paddy \& vegetables was 229.8 \& $92.9 \mathrm{~mm}$; rabi crops sorghum, tobacco, wheat \& vegetables was $355.5,391,427.2 \& 407.1 \mathrm{~mm}$ and hot weather crops paddy, pearl millet $\&$ vegetables was $863.9,600.6 \& 754.7 \mathrm{~mm}$ respectively.

In the stochastic regime, NIR of 19 years as estimated above was used as input in the MATLAB to predict NIR of different crops at Probability of Exceedance (PE) levels of 0.02, 0.05, 0.08, 0.10, 0.15, $0.20,0.25,0.35$ and 0.40 . The goodness of fit was tested by Kolmogorov - Smirnov test and normal distribution was found as best fit. In this test, actual cumulative probability, $\mathrm{P}\left(\mathrm{x}_{\mathrm{i}}\right)$ was calculated using Weibull's formula and theoretical cumulative probability, F(xi) was calculated using normal distribution. The test statistic $\Delta$, which is the maximum of the absolute difference between $\mathrm{P}\left(\mathrm{x}_{\mathrm{i}}\right)$ and $\mathrm{F}\left(\mathrm{x}_{\mathrm{i}}\right)$ was 0.189 while the critical value of the test statistic $\Delta_{\mathrm{o}}$ was 0.2714 for no. of years $(\mathrm{n})=19$ and $10 \%$ significance level. Thus, $\Delta<\Delta_{\mathrm{o}}$, and hence, the hypothesis of normal distribution was accepted. Table-2 shows NIR of different crops of the study area in the stochastic regime. NIR of crops was found to decrease with increase in PE levels. Fig.2, 3, and 4 shows the variation of NIR of kharif, rabi and hot weather crops respectively with different PE levels in the stochastic regime.

\section{Conclusions}

Net irrigation requirement estimation of different crops of the Limbasi Canal command is carried out in the deterministic and stochastic regimes. In the deterministic regime, the estimated average NIR of 19 years for kharif crops paddy \& vegetables was $229.8 \& 92.9 \mathrm{~mm}$; rabi crops sorghum, tobacco, wheat \& vegetables was $355.5,391,427.2 \& 407.1 \mathrm{~mm}$ and hot weather crops paddy, pearl millet \& vegetables was $863.9,600.6 \& 754.7 \mathrm{~mm}$ respectively. In the stochastic regime, NIR estimation of different crops is carried out at Probability of Exceedance (PE) levels of 0.02, 0.05, 0.08, 0.10, 0.15, $0.20,0.25,0.35$ and 0.40 . The goodness of fit was tested by Kolmogorov - Smirnov test and normal distribution was found as best fit. NIR of crops was found to decrease with increase in PE levels in the stochastic regime. 
Table 1: Net Irrigation Requirement of different crops of the study area in the deterministic regime

\begin{tabular}{|c|c|c|c|c|c|c|c|c|c|}
\hline \multicolumn{10}{|c|}{ Net irrigation requirement $(\mathrm{mm})$} \\
\hline Season & Kharif & & Rabi & & & & Hot we & ther & \\
\hline Year & Paddy & Veg & Sorghum & Tobacco & Wheat & Veg & Paddy & $\begin{array}{l}\text { Pearl } \\
\text { millet }\end{array}$ & Veg \\
\hline 1993-1994 & 400.6 & 218.7 & 370.5 & 407.7 & 444.4 & 423.8 & 860.1 & 598.9 & 751 \\
\hline 1994-1995 & 92.4 & 0 & 359.1 & 395.2 & 432.1 & 412.1 & 856.1 & 590.4 & 749.9 \\
\hline 1995-1996 & 317 & 136.8 & 361.8 & 397.8 & 435 & 412.8 & 881.5 & 612.5 & 768.5 \\
\hline 1996-1997 & 137 & 15.6 & 356.5 & 392.2 & 428 & 408 & 856.6 & 590 & 745.8 \\
\hline $1997-1998$ & 119.4 & 58.1 & 335.8 & 368.6 & 403.2 & 385.2 & 882.1 & 610.4 & 775.8 \\
\hline 1998-1999 & 177.1 & 32.4 & 358.5 & 394.7 & 430 & 409.4 & 865.4 & 609.2 & 754.1 \\
\hline 1999-2000 & 296.5 & 203.5 & 359.5 & 395.4 & 430.9 & 410.7 & 854.2 & 599.9 & 741.2 \\
\hline $2000-2001$ & 434.2 & 251.1 & 377.3 & 414.9 & 454.2 & 431.8 & 871.4 & 605.9 & 763.6 \\
\hline 2002-2003 & 356.8 & 146.6 & 375.7 & 413.2 & 452.5 & 430.2 & 861.2 & 597.9 & 755.1 \\
\hline 2003-2004 & 154 & 46 & 357.7 & 393.3 & 430 & 409.3 & 893.1 & 624.8 & 774.8 \\
\hline 2004-2005 & 284.4 & 127 & 344.3 & 378.5 & 413.7 & 392.9 & 862.4 & 599.4 & 759.9 \\
\hline 2005-2006 & 0 & 0 & 348.3 & 382.6 & 418.4 & 398.5 & 824.2 & 564 & 710.8 \\
\hline 2006-2007 & 250.8 & 99.5 & 346.1 & 380.6 & 415.7 & 396.5 & 839 & 585.8 & 729.7 \\
\hline $2007-2008$ & 119.3 & 0 & 350.6 & 385.2 & 421.7 & 400.7 & 837.9 & 583.1 & 733.1 \\
\hline 2008-2009 & 153.2 & 20.6 & 351.4 & 386.3 & 422.5 & 402.2 & 877.5 & 612.7 & 765.9 \\
\hline 2009-2010 & 392.4 & 217.3 & 355 & 390.6 & 426.9 & 408.7 & 918.9 & 640.3 & 808.4 \\
\hline $2010-2011$ & 185.4 & 37.9 & 332.1 & 365.7 & 398.9 & 384.7 & 859.5 & 600.3 & 752.1 \\
\hline 2011-2012 & 256.9 & 104.6 & 358.8 & 394.7 & 431.3 & 410 & 852.2 & 590.8 & 742.5 \\
\hline 2012-2013 & 238.1 & 49.1 & 355.2 & 390.8 & 427.1 & 406.5 & 861.8 & 595.4 & 758.1 \\
\hline Average & 229.8 & 92.9 & 355.5 & 391 & 427.2 & 407.1 & 863.9 & 600.6 & 754.7 \\
\hline
\end{tabular}

(Veg. - Vegetables)

Table 2: Net Irrigation Requirement of different crops of the study area in the stochastic regime

\begin{tabular}{lrrrrrrrrrr}
\hline \multicolumn{10}{c}{ Net irrigation requirement $(\mathrm{mm})$} \\
\hline $\begin{array}{c}\text { Season } \\
\text { Crop }\end{array}$ & Kharif & \multicolumn{1}{c}{ Rabi } \\
$\begin{array}{l}\text { PE } \\
\text { level }\end{array}$ & Paddy & Veg & Sorghum & Tobacco & Wheat & Veg & Paddy & $\begin{array}{r}\text { Pearl } \\
\text { millet }\end{array}$ & Veg \\
\hline 0.02 & 472.2 & 263.2 & 379.4 & 417.4 & 456.3 & 433.4 & 907.3 & 634.4 & 797.1 \\
0.05 & 424 & 229.3 & 374.6 & 412.1 & 450.5 & 428.1 & 898.7 & 627.7 & 788.6 \\
0.08 & 395.7 & 209.4 & 371.9 & 409.1 & 447.1 & 425.1 & 893.6 & 623.7 & 783.7 \\
0.10 & 381.1 & 199.2 & 370.4 & 407.5 & 445.4 & 423.5 & 891 & 621.7 & 781.2 \\
0.15 & 352.1 & 178.9 & 367.6 & 404.3 & 441.9 & 420.3 & 885.8 & 617.6 & 776.1 \\
0.20 & 329.1 & 162.7 & 365.3 & 401.8 & 439.1 & 417.8 & 881.7 & 614.4 & 772.1 \\
0.25 & 309.4 & 148.8 & 363.3 & 399.6 & 436.7 & 415.7 & 878.2 & 611.7 & 768.7 \\
0.35 & 275.3 & 124.8 & 360 & 395.9 & 432.6 & 412 & 872.1 & 606.9 & 762.7 \\
0.40 & 259.7 & 113.9 & 358.4 & 394.2 & 430.8 & 410.3 & 869.3 & 604.8 & 760 \\
\hline
\end{tabular}

(Veg. - Vegetables) 


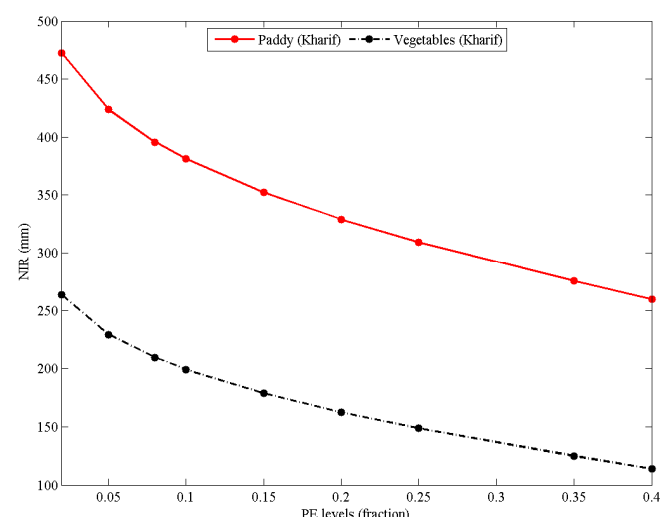

Figure 2: Variation of NIR of kharif crops at different PE levels

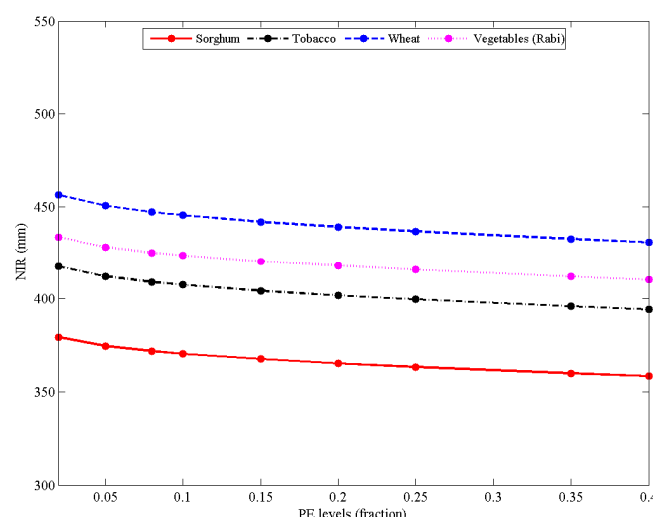

Figure 3: Variation of NIR of rabi crops at different PE levels

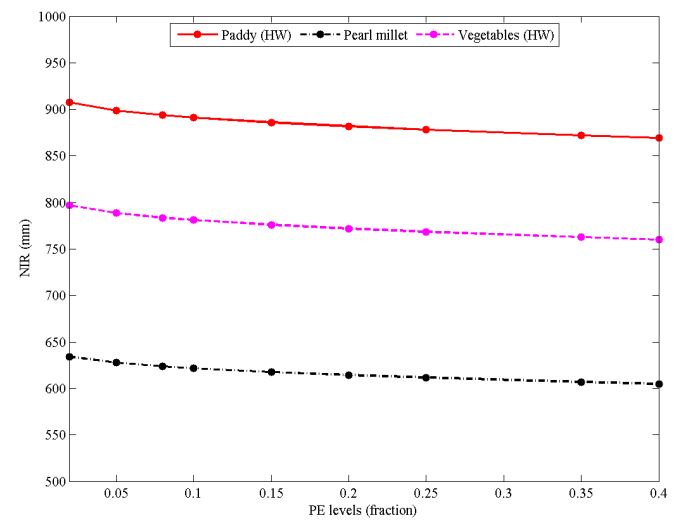

Figure 4: Variation of NIR of hot weather crops at different PE levels

\section{Acknowledgement}

Authors express their sincere thanks to the officials of Gujarat Engineering Research Institute Vadodara, Mahi Irrigation Circle office - Nadiad, Water And Land Management Institute (WALMI) Anand, and Department of Agricultural Meteorology, B. A. College of Agriculture, Anand Agricultural University - Anand for providing necessary data and supporting the research.

\section{References}

[1] M.V.S.S. Giridhar, and G.K. Viswanadh, "Estimating of Reference Evapotranspiration for an Irrigation Project Site in Andhra Pradesh, India" In Proceedings of International Conference on Environmental Management (pp. 216-223), January 2005.

[2] M.V.S.S. Giridhar, and G.K. Viswanadh, "Comparison of reference evapotranspiration equations in Andhra Pradesh, India" In Proceedings of International conference at Omaha, conducted by ASCE, EWRI, Nebraska, USA, 2006 
[3] D. Jhajharia, and S.D. Dhiman, "Comparison of pan evaporation and ET estimates under humid climatic conditions of Agartala (Tripura) and Umiam (Meghalaya)" Journal of Soil Water Conservation, vol. 5(4), pp. 32-37, 2006

[4] A. Singh, P. Krause, S.N. Panda, and W.A. Flugel, "Rising water table: A threat to sustainable agriculture in an irrigated semi-arid region of Haryana, India" Agricultural Water Management, vol. 97(10), pp. 1443-1451, 2010.

[5] A. Singh, "Estimating long-term regional groundwater recharge for the evaluation of potential solution alternatives to waterlogging and salinisation" Journal of Hydrology, vol. 406(3-4), pp. 245-255, 2011.

[6] S.K. Raul, S.N. Panda, and P.M. Inamdar,"Sectoral conjunctive use planning for optimal cropping under hydrological uncertainty" Journal of Irrigation and Drainage Engineering, vol. 138(2), pp. 145-155, 2011. doi: 10.1061/(ASCE)IR.1943-4774.0000393

[7] S.S. Khandelwal, and S.D. Dhiman, "Reference crop evapotranspiration : A comparative study" Proceedings of National Conference on Recent Advances in Civil and Structural Engineering,(RACSE '14)",Jointly Organized by A.D.Patel Institute of Technology and Birla Vishvakarma MahaVidyalaya, Vallabh Vidya Nagar, Gujarat, India,Vol. II, 87-92, April 2014. ISBN 978-81-927554-1-0

[8] K. Djaman, S. Irmak, and K. Futakuchi, "Daily reference evapotranspiration estimation under limited data in Eastern Africa" Journal of Irrigation and Drainage Engineering, 06016015, 2016.

[9] D.V. Raut, and S.B. Jadhav, "Use of computer software for comparison of crop water requirements to actual water applied in canal command area of Jayakwadi project" International Journal of Agricultural Engineering, vol. 5(1), pp. 37-40, 2012.

[10] R. Babu Ganesh, J. Veeranna, K.N. Kumar Raja and I.B. Rao, "Estimation of water requirement for different crops using CROPWAT model in Anantapur region.Asian" J. Environ. Sci., vol. 9(2), pp. 75-79, 2014.

[11] S.S. Khandelwal, and S.D. Dhiman, "Irrigation water requirements of different crops in Limbasi branch canal command area of Gujarat" Journal of Agrometeorology, vol. 17(1), pp. 114-117, 2015.

[12] R. Mehta, and V. Pandey, "Crop water requirement $\left(\mathrm{ET}_{\mathrm{c}}\right)$ of different crops of middle Gujarat" J.of Agrometeorology, vol. 18(1), pp. 83-87, 2016.

[13] L.N. Sethi, S.N. Panda, M.K. Nayak, "Optimal crop planning and water resources allocation in a coastal groundwater basin, Orissa, India" Agricultural Water Management, vol. 83(3), pp. 209220, 2006. doi:10.1016/j.agwat.2005.11.009

[14] N. Saruwatari, and A. Yomota, "Forecasting system of irrigation water on paddy field by fuzzy theory".Agricultural Water Management, vol. 28(2), pp. 163-178, 1995.

[15] L.N. Sethi, D.N. Kumar, S.N. Panda, and B.C. Mal, "Optimal crop planning and conjunctive use of water resources in a coastal river basin" Water resources management, vol. 16(2), pp. 145-169, 2002.

[16] S.D. Dhiman, "Net irrigation water requirement estimation using Fuzzy Logic "Journal of Applied Hydrology, Vol. XXV,pp. 48-52, Jan-April, 2012, ISSN 0971 - 670X

[17] S. Multsch, J.F. Exbrayat, M. Kirby, N.R. Viney, H.G. Frede, and L. Breuer, "Reduction of predictive uncertainty in estimating irrigation water requirement through multi-model ensembles and ensemble averaging" Geoscientific Model Development, vol. 8(4), pp. 1233-1244, 2015

[18] Mahi Irrigation Circle, Nadiad. "Index map of Limbasi canal" soft copy.

[19] Department of Agricultural Meteorology, B. A. College of Agriculture, Anand Agricultural University, Anand. "Weather data of Navagam wetaher station" soft copy.

[20] Land irrigability appraisal report for the area under command of Limbasi branch canal command - Gujarat Engineering Research Institute (GERI) - Vadodara, 2000, 1-3, report, unpublished.

[21] G.H. Hargreaves, and Z.A. Samani, "Reference crop evapotranspiration from temperature" Applied Engineering in Agriculture, vol. 1(2), pp. 96-99, 1985.

[22] A.M. Michael, "Irrigation - Theory and Practice, $2^{\text {nd }}$ edition,New Delhi, India. 2011, pp. 738 "Mean monthly extra-terrestrial radiation $\mathrm{R}_{\mathrm{a}}$ expressed in equivalent evaporation : $\mathrm{mm} / \mathrm{day}$, Table D-4"

[23] Water and Land Management Institute, Anand, Crop coefficient $\left(\mathrm{K}_{\mathrm{c}}\right)$ of different crops grown in Gujarat State. Format-4, Report- unpublished

[24] N.G. Dastane, "Effective rainfall in irrigated agriculture" FAO Irrigation and Drainage Papers (FAO), 1978. 